Article

\title{
Comparative Risk Assessment of Three Native Heliotropium Species in Israel
}

\author{
Jakob A. Shimshoni ${ }^{1, * \mathbb{C}}$, Shimon Barel ${ }^{2}$ and Patrick P. J. Mulder ${ }^{3}$ \\ 1 Department of Food Quality \& Safety, Institute for Postharvest and Food Sciences, \\ Agricultural Research Organization, Volcani Center, Rishon LeTsyion 753593, Israel \\ 2 Department of Toxicology, Kimron Veterinary Institute, Bet Dagan 50250, Israel; Shimonba@moag.gov.il \\ 3 Wageningen Food Safety Research, Wageningen University \& Research, P.O. Box 230, \\ 6700 AE Wageningen, The Netherlands; patrick.mulder@wur.nl \\ * Correspondence: jakobs@volcani.agri.gov.il; Tel.: +972-50-6243961; Fax: +972-3-9681730
}

check for

updates

Citation: Shimshoni, J.A.; Barel, S.; Mulder, P.P.J. Comparative Risk Assessment of Three Native Heliotropium Species in Israel. Molecules 2021, 26, 689. https:// $10.3390 /$ molecules 26030689

Academic Editor: Stefano Dall'Acqua Received: 15 December 2020

Accepted: 25 January 2021

Published: 28 January 2021

Publisher's Note: MDPI stays neutral with regard to jurisdictional claims in published maps and institutional affiliations.

Copyright: (c) 2021 by the authors. Licensee MDPI, Basel, Switzerland. This article is an open access article distributed under the terms and conditions of the Creative Commons Attribution (CC BY) license (https:// creativecommons.org/licenses/by/ $4.0 /)$.

\begin{abstract}
Pyrrolizidine alkaloids (PAs) are genotoxic carcinogenic phytotoxins mostly prevalent in the Boraginaceae, Asteraceae and Fabaceae families. Heliotropium species (Boraginaceae) are PA-producing weeds, widely distributed in the Mediterranean region, that have been implicated with lethal intoxications in livestock and humans. In Israel, H. europaeum, H. rotundifolium and H. suaveolens are the most prevalent species. The toxicity of PA-producing plants depends on the PA concentration and composition. PAs occur in plants as mixtures of dozens of various PA congeners. Hence, the risk arising from simultaneous exposure to different congeners has to be evaluated. The comparative risk evaluation of the three Heliotropium species was based on recently proposed interim relative potency (iREP) factors, which take into account certain structural features as well as in vitro and in vivo toxicity data obtained for several PAs of different classes. The aim of the present study was to determine the PA profile of the major organ parts of H. europaeum, H. rotundifolium and H. suaveolens in order to assess the plants' relative toxic potential by utilizing the iREP concept. In total, 31 different PAs were found, among which 20 PAs were described for the first time for $H$. rotundifolium and $H$. suaveolens. The most prominent PAs were heliotrine- $N$-oxide, europine- $N$ oxide and lasiocarpine- $N$-oxide. Europine- $N$-oxide displayed significant differences among the three species. The PA levels ranged between 0.5 and $5 \%$ of the dry weight. The flowers of the three species were rich in PAs, while the PA content in the root and flowers of H. europaeum was higher than that of the other species. H. europaeum was found to pose a higher risk to mammals than H. rotundifolium, whereas no differences were found between $H$. europaeum and $H$. suaveolens as well as $H$. suaveolens and $H$. rotundifolium.
\end{abstract}

Keywords: Heliotropium europaeum; suaveolens; rotundifolium; pyrrolizidine alkaloids; interim relative potency factor

\section{Introduction}

Pyrrolizidine alkaloids (PAs) are secondary plant metabolites that function as chemical defense compounds against various herbivores [1-3]. They are highly prevalent in the plant families of Boraginaceae, Asteraceae (Senecio and Eupatorieae tribes) and Fabaceae (Crotalarieae tribe). More than 660 PA and PA-N-oxides have been identified and these have been estimated to occur in over 6000 plants [1-3]. PAs are composed of a saturated or 1,2-unsaturated necine base esterified with one or two necic acids [1,2]. Common PA types occurring in the Heliotropium genus are depicted in Figure 1 [3]. In general, PAs occur in two forms, namely, as the free tertiary base and their corresponding $N$-oxide.

Many PAs exhibit genotoxic effects in humans and farm animals targeting mainly the liver [4-7]. Most 1,2-dehydro PAs are pro-toxins, requiring metabolic activation by cytochrome $\mathrm{P} 450$ to generate a pyrrolic ester as the reactive electrophilic intermediate that 


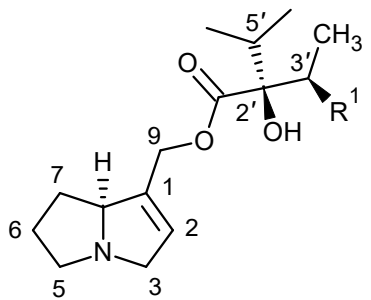

$\mathrm{R}^{1}=\mathrm{H} \quad$ Supinine (1)

$\mathrm{R}^{1}=\mathrm{OH} \quad$ Heleurine (2) subsequently reacts with proteins and nucleic acids [6,7]. Since, upon ingestion, PA-Noxides are reduced in the gut/liver to their corresponding free bases, both PA forms are considered to be toxic $[2,7,8]$. The toxicity of PA-producing plants mostly depends on the absolute PA concentration but also on the plants' PA composition, as the toxic potential of individual PAs and their $N$-oxides widely differs [4,7]. The structural features determining the toxic potencies of PAs have been extensively studied and reviewed $[2,4,9]$.
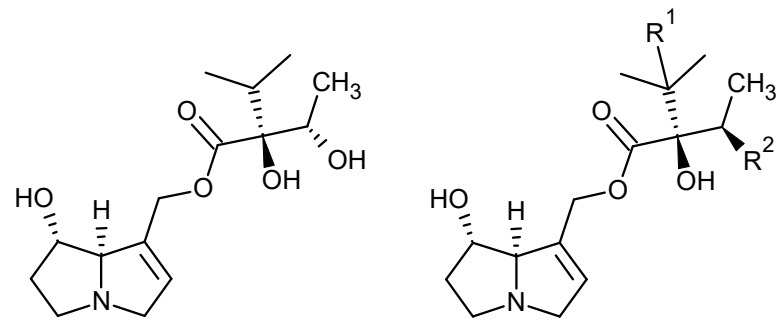

Echinatine (3)

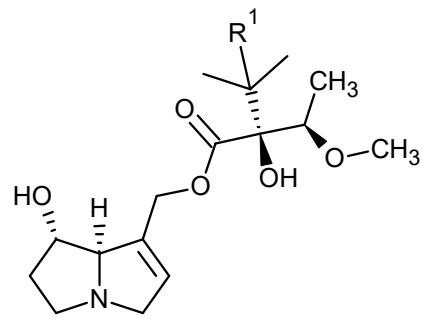

$\mathrm{R}^{1}=\mathrm{H}$

$\mathrm{R}^{1}=\mathrm{OH}$

$\mathrm{R}^{1}=\mathrm{OAC}$
Heliotrine (7)

Europine (8)

5'-Acetyleuropine (9)
$\mathrm{R}^{1}=\mathrm{H}, \mathrm{R}^{2}=\mathrm{OH}$
$\mathrm{R}^{1}=\mathrm{H}, \mathrm{R}^{2}=\mathrm{OAc}$
$\mathrm{R}^{1}=\mathrm{OH}, \mathrm{R}^{2}=\mathrm{OH}$

Rinderine (4)
3'-Acetylrinderine (5)
5'-Hydroxyrinderine (6)

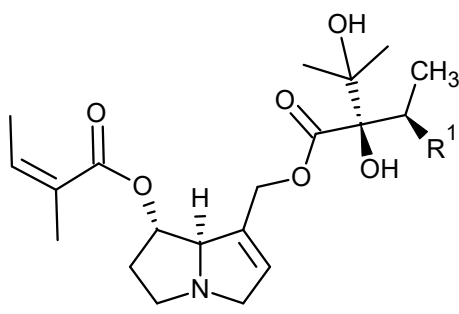

$\mathrm{R}^{1}=\mathrm{OH} \quad$ Heliosupine (10)

$\mathrm{R}^{1}=\mathrm{OAc} \quad 3^{\prime}$-Acetylheliosupine (11)

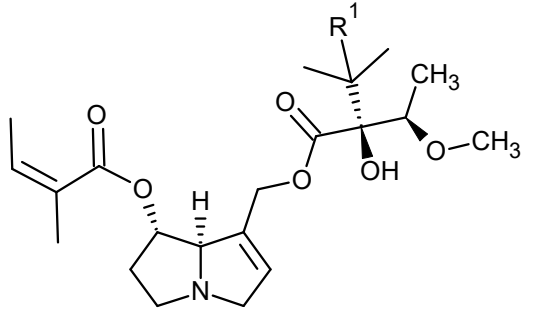

$\mathrm{R}^{1}=\mathrm{H}$

$\mathrm{R}^{1}=\mathrm{OH}$

7-Angeloylheliotrine (12)

Lasiocarpine (13)

$\mathrm{R}^{1}=\mathrm{OAC}$

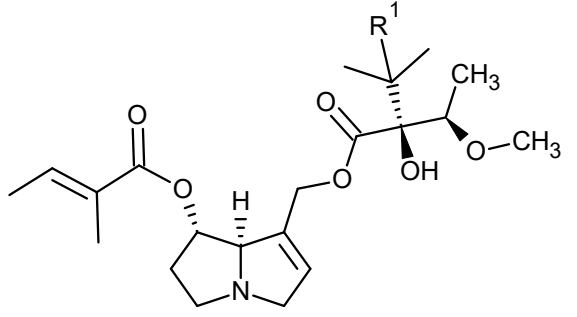

$\mathrm{R}^{1}=\mathrm{OH} \quad$ 7-Tigloyleuropine (15)

$\mathrm{R}^{1}=\mathrm{OAc} \quad 5^{\prime}$-Acetyl-7-tigloyleuropine (16)
$\overbrace{}^{\mathrm{O}}$

Angelic acid<smiles>CC=C(C)C(=O)O</smiles>

Tiglic acid

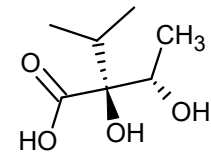

(-)-Viridifloric acid

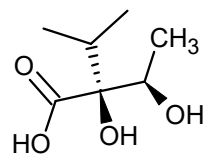

(+)-Trachelantic acid

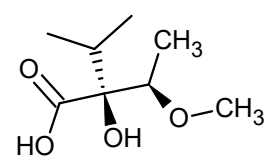

Heliotric acid

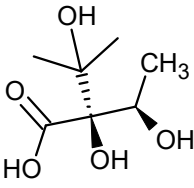

Echimidinic acid

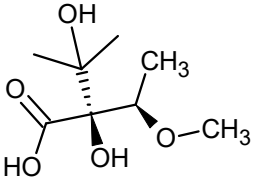

Lasiocarpic acid

Figure 1. Pyrrolizidine alkaloids (PAs) and corresponding necic acids commonly found in Heliotropium species. The corresponding PA-N-oxide forms are not shown.

PA-containing plants commonly grow in pastures and agricultural fields, resulting in occasional cross-contamination of crops and agricultural produce $[1,3,4]$. As PAs occur as mixtures of dozens of various PA congeners, the risk arising from simultaneous exposure to different congeners has to be evaluated $[9,10]$. Although the genotoxic potency of different congeners may vary substantially by several orders of magnitude, the current approach to assess the risk of PA mixtures in a sample is to assign to all of them the same potency as the most toxic congeners (namely, lasiocarpine or riddelliine), resulting in a clear risk over-estimation $[9,10]$.

Recently, Merz and Schrenk suggested assigning interim relative potency (iREP) factors to PA congeners of certain structural features [9]. In brief, this approach is based on structural considerations together with acute toxicity data from rodents, cytotoxicity data in mammalian cell cultures and genotoxicity data in Drosophila, obtained for a limited number of PAs. The iREP factors range from 1.0 for the most toxic PAs to 0.01 for the least toxic congeners [9]. The limited available in vivo and in vitro toxicity data indicate 
that cyclic PA di-esters and 7S-open-chained PA di-esters (compounds 10-16 in Figure 1) are markedly more toxic than 7R-open-chained di-esters followed by 7S PA mono-esters (compounds 1-9) [3,9,10].

Heliotropium species are PA-producing weeds, widely distributed in the Mediterranean region, that have been implicated with lethal PA intoxications in livestock and humans [11-18]. In Israel, 14 different Heliotropium species have been reported, with $H$. europaeum, $H$. rotundifolium and $H$. suaveolens being frequently found in pastures [19-21]. During February 2014, a herd of 73 replacement mixed breed beef cattle (15-18 months old) from the Galilee region of Israel were fed for six weeks a total mixed ration containing hay contaminated with $15 \%$ Heliotropium europaeum, resulting in a mortality rate of $33 \%$ over a period of 63 days [17]. In nearby agricultural fields, used primarily for hay production, two additional Heliotropium species, namely, $H$. suaveolens and $H$. rotundifolium, have been found in high abundance. The total PA content and composition might vary among different Heliotropium species as well as being affected by external factors such as climate, geographic location, season and plant organ [4,22-25].

The aims of the present study were: (1) to investigate the PA composition and concentration in the major organ parts (root, stem, leaf and inflorescence) of the most abundant Heliotropium species (H. europaeum, H. rotundifolium and H. suaveolens), by liquid chromatography coupled to tandem mass spectrometry (LC-MS/MS) analysis and (2) to perform a comparative risk assessment of the three Heliotropium species based on the novel iREP factor concept, in order to classify each species in terms of potential hazard to farm animals and humans.

\section{Results and Discussion}

Pyrrolizidine alkaloids are not only found throughout the plant kingdom in a staggering variety of chemical structures, but they may also occur in a single plant in a highly complex composition. For instance, Senecio jacobaea has been reported to produce at least 37 different PAs and the number of identified PAs in S. pterophorus even exceeds 50 analogues $[26,27]$. The development of highly sensitive mass spectrometric techniques such as LC-MS/MS, which allow the simultaneous measurement of free base PAs and PA-N-oxides, has greatly facilitated the exploration of plant PA profiles. In our study on the poisoning of cattle fed with feed contaminated with high amounts of H. europaeum, we could show the presence of at least 30 PAs (including 15 PA- $N$-oxide forms) [17]. The increased availability of PA reference standards (18 were available for this study) has greatly facilitated the identification and quantification of the major metabolites present in the three species and assisted in the tentative identification of those metabolites for which no analytical standard was available.

\subsection{PAs Identified in H. europaeum, H. rotundifolium and H. suaveolens}

Heliotropium europaeum, H. rotundifolium and H. suaveolens belong to the "Old World" clade within the Heliotropium genus [28]. Other important members of this clade, which also occur in Israel, are $H$. bovei, $H$. hirsutissimum, and H supinum. Based on their close phylogenetic relationship, their PA profiles may be expected to be rather similar. A comprehensive PA profile of the Boraginaceae family was recently reviewed by El-Shazly and Wink, summarizing the available information on the present status of PAs regarding the structure, distribution, chemistry, chemotaxonomic significance and biological properties [3]. El-Shazly and Wink reported, for H. europaeum, europine, acetyleuropine, heleurine, heliotrine, 7-angeloylheliotrine, lasiocarpine, $5^{\prime}$-acetyllasiocarpine and supinine as constituents [3]. For H. rotundifolium, europine, 5'-acetyleuropine, heliotrine and lasiocarpine, and for $H$. suaveolens, echinatine, rinderine, heliotrine and lasiocarpine have been reported [3]. H. bovei reportedly contains europine, 7-acetyleuropine, lasiocarpine and $5^{\prime}$-acetyllasiocarpine; $H$. hirsutissimum contains europine, heliotrine, heleurine, lasiocarpine, $3^{\prime}$-acetyllasiocarpine, $5^{\prime}$-acetyllasiocarpine and supinine; and $H$. supinium contains echinatine, heliosupine, heliotrine, 7-angeloylheliotridine, lasiocarpine and supinine [3]. 
In this study, a total of 31 different PAs (15 free base forms and $16 \mathrm{~N}$-oxides) were detected in the three species. Most of these compounds have been described for the three closely related species as discussed above. The chemical structures of the free base PAs present in the three species are given in Figure 1, while their corresponding $\mathrm{N}$-oxide forms can be derived by covalently attaching an oxygen atom to the nitrogen atom at position 4. The 7-angeloylheliotrine free base was not detected in the plant extracts. LC-MS/MS chromatograms representative of a H. europaeum extract are shown in Figure 2.

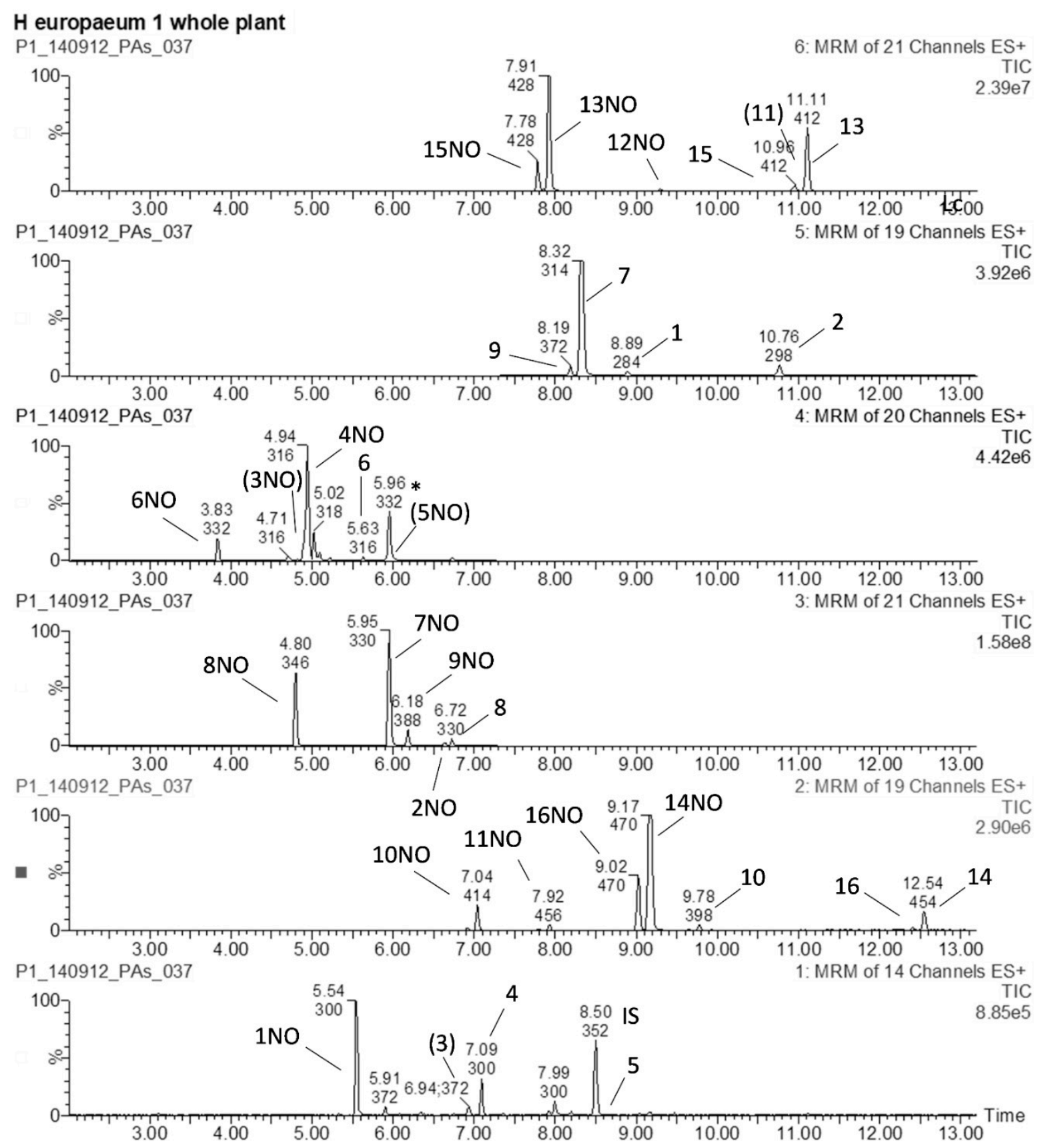

Figure 2. LC-MS/MS multiple reaction monitoring (MRM) chromatograms of a H. europaeum extract (whole plant). Annotation is as shown in Figure $1 . \mathrm{NO}=$ the $\mathrm{N}$-oxide form. ${ }^{*}$ denotes the ${ }^{13} \mathrm{C} 2$-isotopomer of $7 \mathrm{NO}$. IS $=$ internal standard. Compounds between brackets are masked in the chromatogram.

Derivatives of rinderine and heliosupine have so far been reported only in $\mathrm{H}$. indicum, H. peruvianum, H. transalpinum, H. supinum and H. europaeum [3,17]. The identity of rinderine could be confirmed by comparison with an authentic standard, but a definite 
assignment of the rinderine derivatives could not be made, since the obtained mass fragmentation spectra could not exclude the possibility of the echinatine structure. However, based on the fact that (+)-trachelanthic acid, which is the necic acid in rinderine, has the same stereochemistry as heliotric acid, the necic acid in heliotrine, its presence was considered more likely than the echinatine structure, which is esterified with (-)-viridifloric acid and for which no heliotrine counterpart is known. Similarly, the definitive structure for the less abundant isomer of lasiocarpine and $5^{\prime}$-acetyllasiocarpine could not be derived, but it is highly plausible that it contains a tigloyl ester at C-7 instead of the angeloyl ester.

\subsection{Distribution and Composition of PAs in Heliotropium Species}

The flowers of all three species revealed the highest PAs concentration (Table 1). The PAs concentration in the roots of $H$. europaeum was up to 3 times higher than in the corresponding roots of $H$. suaveolens and H. rotundifolium (Table 1 ). No significant differences in the PAs levels were observed between the leaves and stems in the three species. The PA tissue distribution in H. europaeum roughly resembles the organ-specific distribution of several Heliotropium species (H. curassavicum, H. spathulatum and H. indicum) reported in earlier studies [29,30]. Preferential accumulation of PAs in the flowers is also known from other species, e.g., Senecio vulgaris [31]. All major organs of the three Heliotropium species revealed similar abundance of free PA bases and PA- $N$-oxides, with PA-N-oxides constituting more than $94 \%$ of the total PAs in all major tissues analyzed.

The detected PAs and their corresponding $\mathrm{N}$-oxides were classified according to their necine base and the type and number of esterified necic acids as follows:

The supinine-type PAs included supinine, heleurine and their corresponding $N$-oxides; the heliotrine-type PAs included echinatine, rinderine, 5'-hydroxy-rinderine, 7-acetylrinderine, heliotrine, europine, $5^{\prime}$-acetyl-europine and their corresponding $N$-oxides; and the lasiocarpine-type PAs comprised heliosupine, $3^{\prime}$-acetyl-heliosupine, lasiocarpine, isolasiocarpine, 5'-acetyl-lasiocarpine, iso-acetyl-lasiocarpine and their corresponding $\mathrm{N}$ oxides as well as 7-angeloylheliotrine- $\mathrm{N}$-oxide (Figure 1 ).

H. europaeum and $H$. suaveolens revealed a similar pattern of relative PA abundances with heliotrine-type PAs and lasiocarpine-type Pas, accounting for $72-89 \%$ and $8.7-30 \%$ of total Pas, respectively (Table 1). H. rotundifolium, however, displayed a markedly different PAs profile, with more than $90 \%$ of the total PAs found in all major plant tissues belonging to the heliotrine-type PAs. The supinine-type PAs comprised only a small proportion in all tissues analyzed $(<4 \%)$. The PA compositions in each of the major plant tissues of the three Heliotropium species studied are illustrated in Figure 3 and depicted in Supplementary Table S4. The most abundant PAs found in all plant tissues were europine- $\mathrm{N}$-oxide, heliotrine- $\mathrm{N}$ oxide and lasiocarpine- $\mathrm{N}$-oxide, constituting more than $85 \%$ of the total PAs in accordance with the study results published by $\mathrm{O}^{\prime}$ Dowd and Edgar [22]. The most prominent PA in all the major plant tissues of $\mathrm{H}$. rotundifolium and $\mathrm{H}$. suaveolens was europine- $\mathrm{N}$-oxide (60-83\% for $H$. rotundifolium and $43-57 \%$ for $H$. suaveolens) followed by heliotrine- $N$-oxide (3-14\% for $H$. rotundifolium and $16-29 \%$ for $H$. suaveolens) and lasiocarpine- $N$-oxide $(0.1-5 \%$ for $H$. rotundifolium and $5-18 \%$ for $H$. suaveolens). However, the stems and flowers of H. europaeum revealed comparable concentrations of heliotrine- $\mathrm{N}$-oxide and europine- $\mathrm{N}$-oxide, while the mean relative abundance of heliotrine- $\mathrm{N}$-oxide in the roots and leaves was about twice the relative abundance of europine- $\mathrm{N}$-oxide (Supplementary Table S4).

Europine- $N$-oxide was the only alkaloid displaying a statistically significant interaction between major plant tissues and Heliotropium species for all tissues analyzed $(\mathrm{F}=3.157$, $\mathrm{Df}=6, p<0.01$; Supplementary Table S4).

\subsection{Relative Risk Assessment of the Aerial Parts of Heliotropium Species}

The toxic potential of PA-producing weeds depends not only on the total PA concentrations in the plant, but also on the relative abundance of the various individual PAs, due to their differences in their toxic potential, as was demonstrated in various studies $[9,10]$. For instance, 1,2-unsaturated di-esters such as lasiocarpine-type PAs were demonstrated to 
be substantially more toxic than the 1,2-unsaturated mono-esters, such as heliotrine-type PAs and supinine-type PAs $[3,9,10]$.

The lasiocarpine-type PAs content of $H$. europaeum was significantly higher than the corresponding content in H. rotundifolium $(p<0.05)$, whereas the remaining multiple comparisons between the three species in relation to their PA content revealed no significant differences (Table 2). Notwithstanding, the total PA content of the aerial parts of the plant among the three species was not significantly different, which could be attributed to the relatively high variability of the PA content within each species (Table 2). Congruent with the lasiocarpine-type content, the relative toxic potency, obtained by the summation of the product PA type content and the iREP, of H. europaeum was significantly higher than the corresponding value of $H$. rotundifolium, whereas no statistical differences were observed for the remaining multiple comparisons (Table 2). The heliotrine- and lasiocarpine-type PAs contributed more than $98 \%$ to the relative toxic potency of the Heliotropium species studied, while the contribution of the supinine-type PAs was negligible $(\leq 1.5 \%)$, due to lower abundance and relative toxicity. Although $H$. suaveolens displayed a similar PA content and composition to H. europaeum, no statistical difference was found in the relative toxic potency of $H$. suaveolens and $H$. rotundifolium (Table 2). It is reasonable to assume that the relatively low sample size $(n=5)$ limited the chance of detecting a true difference in the total PA content as well as in the relative toxic potency between $H$. rotundifolium and H. suaveolens. 


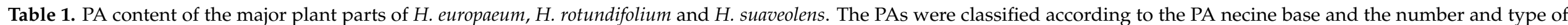
esterifying necic acids.

\begin{tabular}{|c|c|c|c|c|c|c|c|c|c|c|c|c|}
\hline & \multicolumn{4}{|c|}{ H. europaeum ${ }^{a}$} & \multicolumn{4}{|c|}{ H. rotundifolium ${ }^{b}$} & \multicolumn{4}{|c|}{ H. suaveolens ${ }^{\mathrm{c}}$} \\
\hline & Root & Stem & Leaf & Flower & Root & Stem & Leaf & Flower & Root & Stem & Leaf & Flower \\
\hline $\begin{array}{l}\text { Total PA content (mean } \\
\pm \mathrm{SD})(\mathrm{g} / \mathrm{kg} \text { dry weight) }\end{array}$ & $23 \pm 13^{*}$ & $5 \pm 5$ & $13 \pm 12$ & $53 \pm 15^{* *}$ & $7 \pm 3$ & $12 \pm 2$ & $11 \pm 7$ & $29 \pm 7^{* *}$ & $7 \pm 5$ & $11 \pm 10$ & $13 \pm 17$ & $40 \pm 20^{* *}$ \\
\hline$\%$ Total PA bases & $5.8 \pm 3.2$ & $4.2 \pm 1.7$ & $3.4 \pm 2.1$ & $4.2 \pm 1.5$ & $2.9 \pm 0.1$ & $2.7 \pm 2.0$ & $1.5 \pm 0.2$ & $4.2 \pm 0.7$ & $5.7 \pm 3.1$ & $2.2 \pm 1.0$ & $2.5 \pm 0.3$ & $4.2 \pm 1.9$ \\
\hline$\%$ Total PA-N-oxides & $94.2 \pm 3.2$ & $95.8 \pm 1.7$ & $96.6 \pm 2.1$ & $95.8 \pm 1.5$ & $97.1 \pm 0.1$ & $97.3 \pm 2.0$ & $98.5 \pm 0.2$ & $95.8 \pm 0.7$ & $94.3 \pm 3.1$ & $97.8 \pm 1.0$ & $97.5 \pm 0.3$ & $95.8 \pm 1.9$ \\
\hline$\%$ Supinine-type & $0.5 \pm 0.4$ & $0.7 \pm 0.3$ & $1.2 \pm 0.5$ & $1.7 \pm 0.8$ & $0.9 \pm 0.8$ & $0.7 \pm 0.5$ & $0.3 \pm 0.1$ & $2.2 \pm 0.5$ & $0.5 \pm 0.6$ & $1.7 \pm 0.9$ & $3.4 \pm 4.2$ & $2.3 \pm 1.3$ \\
\hline$\%$ Heliotrine-type & $76 \pm 11$ & $82 \pm 6$ & $75 \pm 14$ & $86 \pm 7$ & $90.3 \pm 8.3^{\mathrm{d}}$ & $97.7 \pm 1.5^{\mathrm{d}}$ & $99.6 \pm 0.3^{d}$ & $97.0 \pm 1.3^{\mathrm{d}}$ & $79 \pm 11$ & $89 \pm 7$ & $73 \pm 22$ & $85 \pm 15$ \\
\hline$\%$ Lasiocarpine-type & $23 \pm 12$ & $17 \pm 6$ & $24 \pm 14$ & $12 \pm 7$ & $8.8 \pm 7.5^{\mathrm{e}}$ & $1.5 \pm 2.0^{\mathrm{e}}$ & $0.1 \pm 0.2^{\mathrm{e}}$ & $0.7 \pm 0.8$ & $21 \pm 9$ & $9 \pm 7$ & $24 \pm 25$ & $13 \pm 14$ \\
\hline
\end{tabular}

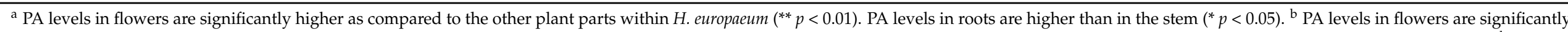

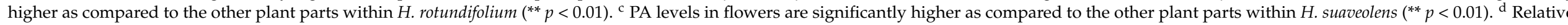

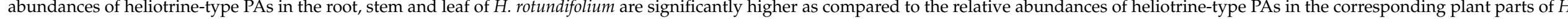

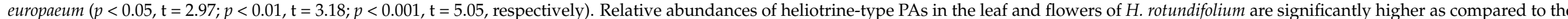

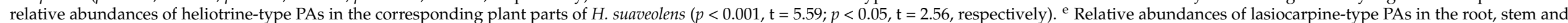

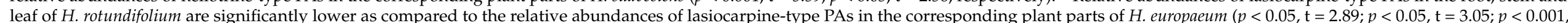

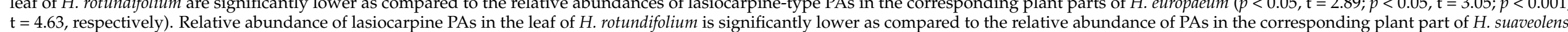
$(p<0.001, \mathrm{t}=4.71)$.

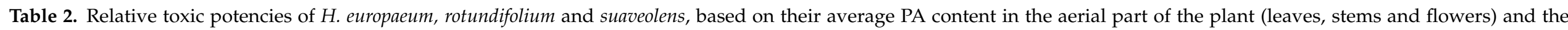
corresponding relative toxic equivalent of each PA type.

\begin{tabular}{|c|c|c|c|c|c|c|c|}
\hline & \multicolumn{3}{|c|}{ PA Content of Aerial Part ${ }^{a}$ in $\mathrm{g} / \mathrm{kg}$} & \multirow{2}{*}{$\begin{array}{c}\text { Interim Relative } \\
\text { Potency Factor (iREP) }\end{array}$} & \multicolumn{3}{|c|}{ Relative Toxic Potency (Concentration x iREP) } \\
\hline & H. europaeum & H. rotundifolium & H. suaveolens & & H. europaeum & H. rotundifolium & H. suaveolens \\
\hline Supinine-type content & $0.4 \pm 0.3(1.4 \%)$ & $0.3 \pm 0.5(1.7 \%)$ & $0.5 \pm 0.8(2 \%)$ & 0.3 & $0.12 \pm 0.09(1 \%)$ & $0.09 \pm 0.15(1.5 \%)$ & $0.15 \pm 0.2(1.5 \%)$ \\
\hline Heliotrine-type content & $24.5 \pm 15(83.3 \%)$ & $16.6 \pm 7.2(97.1 \%)$ & $20.8 \pm 12(85 \%)$ & 0.3 & $7.3 \pm 4.1(62 \%)$ & $5.0 \pm 2.1(95.2 \%)$ & $6.2 \pm 4.4(65 \%)$ \\
\hline Lasiocarpine-type content & $4.5 \pm 2.1(15.3 \%)$ & $0.2 \pm 0.1 *(1.1 \%)$ & $3.2 \pm 2.2(13 \%)$ & 1 & $4.5 \pm 2.2(37 \%)$ & $0.2 \pm 0.1(3.3 \%)$ & $3.2 \pm 2.3(33.5 \%)$ \\
\hline Sum of PA/relative toxic potency ${ }^{b}$ & $29.4 \pm 15$ & $17.1 \pm 7.1$ & $24.5 \pm 12$ & - & $11.9 \pm 4.4$ & $5.3^{* *} \pm 2.2$ & $9.5 \pm 5.1$ \\
\hline
\end{tabular}

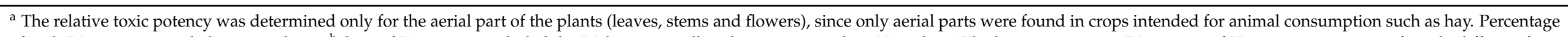

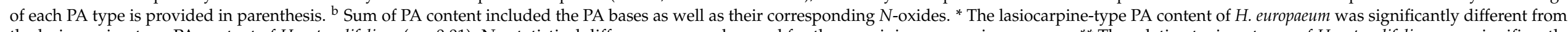

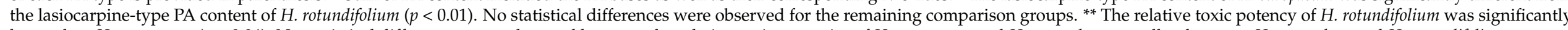
lower than H. europaeum $(p<0.04)$. No statistical differences were observed between the relative toxic potencies of $H$. europaeum and $H$. suaveolens as well as between $H$. suaveolens and $H$. rotundifolium. 

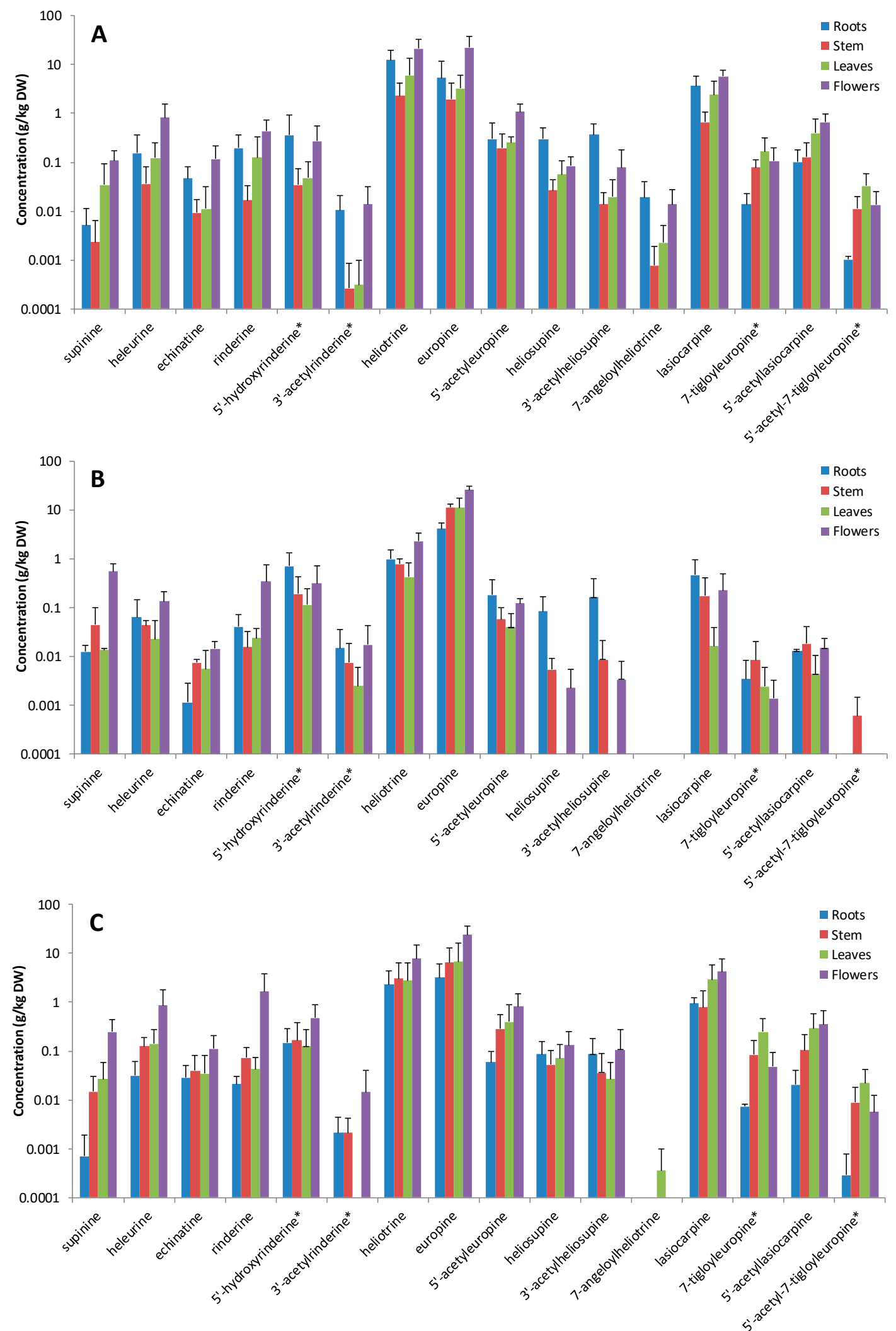

Figure 3. PA composition and the log concentration $(\mu \mathrm{g} / \mathrm{g})$ of the major plant parts (root, stem, leaf and flowers) in (A). $H$. europaeum $(n=5),(\mathbf{B})$ H. rotundifolium $(n=5)$ and $(\mathbf{C})$ H. suaveolens $(n=5)$ * : tentative identification. Concentrations are for the sum of tertiary amines and corresponding $N$-oxides. 


\section{Materials and Methods}

\subsection{Materials, Reagents and Standards}

Formic acid (analytical grade) and ammonia solution (25\%, analytical grade) were obtained from Merck (Darmstadt, Germany). Acetonitrile (LC-MS grade) was from Biosolve (Valkenswaard, The Netherlands). Analytical PA standards (7-acetylintermedine, echimidine, echinatine, europine, heliosupine, heliotrine, intermedine, lasiocarpine, rinderine, and their corresponding N-oxides) were obtained from Phytoplan (Heidelberg, Germany), except for heliotrine, which was obtained from Latoxan (Valence, France). The purity of the analytical standards was $95 \%$ or higher, except for heliotrine that contained approximately $10 \%$ europine. A semi-quantitative result was obtained for PAs, lacking a reference standard, by comparison of the peak area with that of a structurally related standard, as indicated in Supplementary Table S1.

\subsection{Plant Material}

Several individual plant samples of $H$. europaeum, $H$. rotundifolium and $H$. suaveolens were collected in August $2014(n=5)$ during their flowering stage on a pastoral land in the Galilee region near Kibbutz Gazit, Israel ( $32^{\circ} 38^{\prime} 15^{\prime \prime} \mathrm{N} 35^{\circ} 26^{\prime} 49.55^{\prime \prime}$ E). The annual rainfall at the site of collection averaged $577 \mathrm{~mm}$. To account for possible diurnal variations in alkaloid accumulation, plants were harvested between 12:00 and 14:00 p.m. On the same day of collection, the plants were air dried at $50{ }^{\circ} \mathrm{C}$ in an oven for $12 \mathrm{~h}$ and the major plant organs (inflorescence, leaves, stems and roots) were separately milled to a particle size of $<1 \mathrm{~mm}$ (Foss Cyclotech 1093, Hillerød, Denmark). The samples were stored in air-tight plastic bags at $-20^{\circ} \mathrm{C}$ until further processing for LC-MS/MS analysis.

\subsection{Plant Description}

Heliotropium species are annual herbs growing from a taproot and reaching maximum heights near $70 \mathrm{~cm}$. Due to their high morphological resemblance, species identification is often only possible by expert botanists. H. europaeum is a small to medium-sized annual plant, up to $40 \mathrm{~cm}$ high, with a distribution habitat in Israel ranging from the north to the southern Negev [19-21]. The stems and leaves are covered with short and dense hairs, equal in length. The flowers are $2 \mathrm{~mm}$ in diameter, white with a small yellow spot around the pharynx, and the petals are rounded, egg-shaped. The fruit consists of 2-4 irregularly roughened nutlets. The flowering time of H. europaeum is between May and October [19].

$H$. suaveolens is a small to medium-sized weed (height up to $30 \mathrm{~cm}$ ), distributed in Israel mainly on the coastal plain and on the basalt soil in the Golan Heights. The leaves are egg-shaped and display a thin loose cover of short, equally sized trichrome, bestowing them a delicate silvery hue. The flowers are $3-5 \mathrm{~mm}$ in diameter, white and have a small, inconspicuous yellow spot in the pharyngeal tube with rounded petal lobes. In a crosssection, the petiole appears round and hairless on the inside and has sparse hairs on the outside. The flowers give off a delicate and pleasant scent, hence the name of the species. The fruit consists of 2-4 irregularly roughened nutlets. The flowering time of H. suaveolens is between May and December [19].

$H$. rotundifolium is a graying shrub with a solid base, distributed in Israel throughout the country mostly in limestone hills and rock outcrops, but is mostly absent in the southern Negev. The leaves are broad-egg-shaped and round. The stems and leaves are covered with short, dense hairs that impart the whole plant with a strong silvery-gray hue. The inflorescences are long and multi-flowered. The flowers are of $4 \mathrm{~mm}$ in diameter and white, having a small yellow spot at the opening of the flower tube. The petioles are triangular-pointed, with the tip bent and facing the center of the flower. In addition, the petiole is hairy on the outside and completely hairless on the inside. The flowering time of H. rotundifolium is between April and September [19]. 


\subsection{LC-MS/MS Analysis for PA and PA-N-Oxides in Heliotropium Species}

Dried, ground plant material was extracted using a slightly adapted procedure described by Shimshoni et al. [17]. Jacobine was added as an internal standard to check the sample extraction procedure and the analytical performance of LC-MS/MS. Powdered material was extracted with $2 \%$ formic acid solution in a 1 to 100 ratio $(w / v)$. The extract was then filtered and $5 \mu \mathrm{L}$ was diluted 200 times with $2 \mathrm{mM} \mathrm{NH}_{4} \mathrm{OH}$ solution in autosampler vials. PA composition and content of the samples were determined using a Waters Acquity chromatographic system coupled to a Waters Quattro Premier XE tandem mass spectrometer (Waters, Milford, MA, USA), run in multiple reaction monitoring mode (MRM) with positive electrospray ionization. Cone voltage was set at $30 \mathrm{~V}$, desolvation gas temperature at $450{ }^{\circ} \mathrm{C}$, source block temperature at $120^{\circ} \mathrm{C}$ and the argon collision gas pressure at $4.0 \times 10^{-3}$ mbar. Dwell time of the selected transitions was $10 \mathrm{~ms}$ with an interscan delay of $0.5 \mathrm{~ms}$. Separation of PAs was accomplished on a Waters UPLC BEH C18 $(1.7 \mu \mathrm{m}, 150 \times 2.1 \mathrm{~mm})$ analytical column (Waters, Milford, MA, USA), kept at $50{ }^{\circ} \mathrm{C}$ and run at $0.4 \mathrm{~mL} / \mathrm{min}$. A mobile phase consisting of $6.5 \mathrm{mM} \mathrm{NH}_{4} \mathrm{OH}$ in water and $6.5 \mathrm{mM}$ $\mathrm{NH}_{4} \mathrm{OH}$ in acetonitrile was used. The gradient started at $100 \%$ water and was changed linearly to $50 \%$ acetonitrile in $12 \mathrm{~min}$. After $0.2 \mathrm{~min}$, the composition was returned to the starting condition and the column was allowed to equilibrate for another $2.5 \mathrm{~min}$. Mass spectrometric data were processed using Masslynx software, version 4.1 (Waters, Milford, MA, USA).

Representative samples of each species were screened for the presence of novel PAs using parent ion scanning. Typical product fragments were selected such as 120, 122, 138, 156,172 and $254 \mathrm{~m} / \mathrm{z}$. Mass scanning range was from 200 to $500 \mathrm{~m} / \mathrm{z}$ with a mass resolution of $0.1 \mathrm{D}$ and a scan time of $800 \mathrm{~ms}$. Spectra were recorded using a fixed cone voltage of $30 \mathrm{~V}$ and fixed collision energy of $30 \mathrm{eV}$. Compounds producing a protonated molecular ion with an even mass and displaying fragmentation behavior typical for (specific types of) PAs were tentatively identified as PAs. These potential PAs were further identified by collecting individual fragmentation spectra at a collision energy range $(20-40 \mathrm{eV})$. Based on the fragmentation spectra and comparison with literature data [3,7], it was possible to assign chemical structures to the majority of PAs present in the extracts. As isomeric PAs (e.g., rinderine and echinatine) often produce identical fragmentation spectra, it was not possible to discriminate between isomers and, consequently, those assignments are tentative. Supplementary Material S3 presents representative mass spectra of the identified PAs in the Heliotropium extracts, including a tentative assignment of the major fragments present in the mass spectra. All (tentatively) identified compounds have been included in the MRM method, by selecting two product ions (typically the most abundant ones). See Supplementary Table S1 for the mass spectrometric settings selected for each compound. PAs were quantified against a range of calibrant samples $(0-500 \mathrm{ng} / \mathrm{mL})$ containing the available PA standards. Limit of quantification in the plant materials was $1 \mu \mathrm{g} / \mathrm{g}$.

\subsection{Comparative Risk Assessment}

The comparative risk assessment was performed only for the aerial parts of the plant (sum of stem, leaves and inflorescence), since only aerial parts are usually co-harvested with edible crops. The concentration of each congener of the aerial parts of each Heliotropium species was multiplied by its corresponding iREP factor [9]. Summing up these products for each species yielded the overall sum of equivalents per species, e.g., relative toxic potency (Table 2). The sum was then considered as a suitable parameter quantitatively describing the relative toxic potential of each species. According to Merz and Schrenk, the following iREP criteria for the various classes of PAs were used: 7S-mono-esters 0.3 (rinderine- and heliotrine-type) and open-chained 7S-di-esters 1.0 (heliosupine- and lasiocarpine-type) [9]. The corresponding $N$-oxides were assigned the same iREP values as the corresponding PAs, due to their rapid conversion to their corresponding free base under physiological conditions [32,33]. 


\subsection{Statistical Analysis}

Mean values for each PA were determined from 5 replicates of each major organ plant of the three species (flowers, leaves, stems and roots). Differences in PA concentrations among the three Heliotropium species were tested for the same major plant organ (interaction of species with major plant organ) by using a two-way ANOVA test, followed by a Bonferroni multiple comparison test. A $p$ value of $<0.05$ was considered to be significant. Differences in the relative toxic potential (sum of the products of concentration and iREP factor) and the content of PA types between the three Heliotropium species were determined using one-way ANOVA, followed by the Tukey multiple comparison test. A $p$ value of $<0.05$ was considered to be significant.

The statistical tests were performed with GraphPad Prism version 5.04 for Windows (GraphPad Software, La Jolla, CA, USA).

\section{Conclusions}

In this study, LC-MS/MS was used to analyze PAs in the major organ parts of $H$. europaeum, H. rotundifolium and H. suaveolens. The application of LC-MS/MS for the evaluation of PA profiles is expected to further expand the PA composition of known PA-producing plants. Based on the interim relative potency factor concept, $H$. europaeum was found to pose a higher health risk to exposed animals and humans as compared to $H$. rotundifolium, whereas no differentiation in the relative toxic potency could be established for H. suaveolens and H. rotundifolium as well as for H. suaveolens and H. europaeum.

Supplementary Materials: The following are available online: Table S1: Mass spectrometric conditions used and indicative retention times of standards used for pyrrolizidine alkaloids detected in Heliotropium species, Table S2: Pyrrolizidine alkaloids identified in this study in Heliotropium species., Data file S3: MS/MS fragmentation spectra of pyrrolizidine alkaloids detected in Heliotropium species. Collision energy applied is $25 \mathrm{eV}$, Table S4: Relative PA abundance (\%) present in the major plant parts of H. europaeum, H. rotundifolium and H. suaveolens.

Author Contributions: Conceptualization, J.A.S. and S.B.; methodology, J.A.S. and P.P.J.M.; software, P.P.J.M. and J.A.S.; validation, P.P.J.M.; formal analysis, P.P.J.M. and J.A.S.; investigation, J.A.S., S.B. and P.P.J.M.; resources, J.A.S. and P.P.J.M.; data curation, J.A.S.; writing—original draft preparation, J.A.S.; writing - review and editing, J.A.S. and P.P.J.M.; visualization, P.P.J.M. and J.A.S.; supervision, J.A.S.; project administration, J.A.S.; funding acquisition, J.A.S. All authors have read and agreed to the published version of the manuscript.

Funding: The authors J.A.S., S.B., and P.P.J.M. received no funding for this work.

Institutional Review Board Statement: Not applicable.

Informed Consent Statement: Not applicable.

Data Availability Statement: Data is contained within the article or supplementary material.

Acknowledgments: We are sincerely grateful to Yotam Zipper at the Hebrew University of Jerusalem, for the assistance in determining the Heliotropium species and Ephraim Goldin (Gstat, Big-data Predictive-analytics Software, Granit St 6, Petah Tikva 4951405, Israel; goldin@g-stat.com) for the assistance in the statistical analysis.

Conflicts of Interest: The authors declare no conflict of interest.

Sample Availability: Samples of the compounds are not available from the authors.

\section{References}

1. Schramm, S.; Köhler, N.; Rozhon, W. Pyrrolizidine Alkaloids: Biosynthesis, Biological Activities and Occurrence in Crop Plants. Molecules 2019, 24, 498. [CrossRef]

2. Tamariz, J.; Burgueño-Tapia, E.; Vázquez, M.A.; Delgado, F. Pyrrolizidine Alkaloids. Alkaloids Chem. Biol. 2018, 80, 1-314. [CrossRef]

3. El-Shazly, A.; Wink, M. Diversity of Pyrrolizidine Alkaloids in the Boraginaceae Structures, Distribution, and Biological Properties. Diversity 2014, 6, 188-282. [CrossRef] 
4. EFSA Panel on Contaminants in the Food Chain (CONTAM). Scientific opinion on pyrrolizidine alkaloids in food and feed. EFSA J. 2011, 9, 1-134. Available online: http:/ /www.efsa.europa.eu/en/efsajournal/doc/2406.pdf (accessed on 27 October 2020).

5. Edgar, J.A.; Molyneux, R.J.; Colegate, S.M. Pyrrolizidine Alkaloids: Potential Role in the Etiology of Cancers, Pulmonary Hypertension, Congenital Anomalies, and Liver Disease. Chem. Res. Toxicol. 2015, 28, 4-20. [CrossRef]

6. Louisse, J.; Rijkers, D.; Stoopen, G.; Holleboom, W.J.; Delagrange, M.; Molthof, E.; Mulder, P.P.; Hoogenboom, R.L.; Audebert, M.; Peijnenburg, A.A. Determination of genotoxic potencies of pyrrolizidine alkaloids in HepaRG cells using the $\gamma \mathrm{H} 2 \mathrm{AX}$ assay. Food Chem. Toxicol. 2019, 131, 110532. [CrossRef] [PubMed]

7. Ruan, J.; Yang, M.; Fu, P.; Ye, Y.; Lin, G. Metabolic activation of pyrrolizidine alkaloids: Insights into the structural and en-zymatic basis. Chem. Res. Toxicol. 2014, 27, 1030-1039. [CrossRef]

8. Fu, P.P.; Xia, Q.; Lin, G.; Chou, M.W. Pyrrolizidine Alkaloids-Genotoxicity, Metabolism Enzymes, Metabolic Activation, and Mechanisms. Drug Metab. Rev. 2004, 36, 1-55. [CrossRef]

9. Merz, K.-H.; Schrenk, D. Interim relative potency factors for the toxicological risk assessment of pyrrolizidine alkaloids in food and herbal medicines. Toxicol. Lett. 2016, 263, 44-57. [CrossRef]

10. Gao, L.; Rutz, L.; Schrenk, D. Structure-dependent hepato-cytotoxic potencies of selected pyrrolizidine alkaloids in primary rat hepatocyte culture. Food Chem. Toxicol. 2020, 135, 110923. [CrossRef]

11. Prakash, A.S.; Pereira, T.N.; Reilly, P.E.; A Seawright, A. Pyrrolizidine alkaloids in human diet. Mutat. Res. Genet. Toxicol. Environ. Mutagen. 1999, 443, 53-67. [CrossRef]

12. Harper, P.A.W.; Krahenbuhl, R.E.; Christie, B.M. Pyrrolizidine alkaloid poisoning in calves due to contamination of straw by Heliotropium europaeum. Aust. Vet. J. 1985, 62, 382-383. [CrossRef] [PubMed]

13. Hill, B.D.; Gaul, K.L.; Noble, J.W. Poisoning of feedlot cattle by seeds of Heliotropium europaeum. Aust. Vet. J. 1997, 75, 360-361. [CrossRef] [PubMed]

14. Kakar, F.; Akbarian, Z.; Leslie, T.; Mustafa, M.L.; Watson, J.; Van Egmond, H.P.; Omar, M.F.; Mofleh, J. An Outbreak of Hepatic Veno-Occlusive Disease in Western Afghanistan Associated with Exposure to Wheat Flour Contaminated with Pyrrolizidine Alkaloids. J. Toxicol. 2010, 2010, 1-7. [CrossRef] [PubMed]

15. McLennan, M.W.; Dodson, M.E.; Rac, R. Heliotropium poisoning in cattle. Aust. Vet. J. 1972, 48, 480. [CrossRef] [PubMed]

16. Molyneux, R.J.; Gardner, D.; Colegate, S.M.; Edgar, J. Pyrrolizidine alkaloid toxicity in livestock: A paradigm for human poisoning? Food Addit. Contam. Part A Chem. Anal. Control Expo. Risk Assess. 2011, 28, 293-307. [CrossRef]

17. Shimshoni, J.A.; Mulder, P.P.J.; Bouznach, A.; Edery, N.; Pasval, I.; Barel, S.; Khaliq, M.A.-E.; Perl, S. Heliotropium europaeum Poisoning in Cattle and Analysis of Its Pyrrolizidine Alkaloid Profile. J. Agric. Food Chem. 2015, 63, 1664-1672. [CrossRef]

18. Shlosberg, A.; Egyed, M.N.; Nobel, T.A.; Klopfer, U.; Perl, S.; Yakobson, B. First cases in Israel of chronic poisoning in calves caused by ingestion of Heliotropium europaeum. Refuah Vet. 1981, 38, 80-88.

19. Flora of Israel online. The Hebrew University of Jerusalem. 2013. Available online: https://flora.org.il/en/plants/systematics/ heliotropium/ (accessed on 24 November 2020).

20. Wild Flowers of Israel. Available online: http:/ / www.wildflowers.co.il/english/about.asp (accessed on 20 November 2020).

21. Hanson, H.C.; Zohary, M. Plant Life of Palestine, Israel, and Jordan. J. Range Manag. 1962, 15, 339. [CrossRef]

22. O'Dowd, D.J.; Edgar, J.A. Seasonal dynamics in the pyrrolizidine alkaloids of Heliotropium europaeum. Aust. J. Ecol. 2006, 14, 95-105. [CrossRef]

23. Catalfamo, J.L.; Martin, W.B.; Birecka, H. Accumulation of alkaloids and their necines in Heliotropium curassavicum, H. spathulatum and H. indicum. Phytochemistry 1982, 21, 2669-2675. [CrossRef]

24. Frölich, C.; Ober, D.; Hartmann, T. Tissue distribution, core biosynthesis and diversification of pyrrolizidine alkaloids of the lycopsamine type in three Boraginaceae species. Phytochemistry 2007, 68, 1026-1037. [CrossRef] [PubMed]

25. Hartmann, T.; Zimmer, M. Organ-specific Distribution and Accumulation of Pyrrolizidine Alkaloids during the Life History of two Annual Senecio Species. J. Plant Physiol. 1986, 122, 67-80. [CrossRef]

26. Cheng, D.; Kirk, H.; Mulder, P.P.J.; Vrieling, K.; Klinkhamer, P.G.L. Pyrrolizidine alkaloid variation in shoots and roots of segregating hybrids between Jacobaea vulgaris and Jacobaea aquatica. New Phytol. 2011, 192, 1010-1023. [CrossRef]

27. Castells, E.; Mulder, P.P.J.; Perez -Trujillo, M. Diversity of pyrrolizidine alkaloids in native and invasive Senecio pterophorus (Asteraceae): Implications for toxicity. Phytochemistry 2014, 108, 137-146. [CrossRef]

28. Diane, N.; Förther, H.; Hilger, H.H. A systematic analysis of Heliotropium, Tournefortia, and allied taxa of the Heliotropiaceae (Boraginales) based on ITS1 sequences and morphological data. Am. J. Bot. 2002, 89, 287-295. [CrossRef]

29. Crews, C.; Berthiller, F.; Krska, R. Update on analytical methods for toxic pyrrolizidine alkaloids. Anal. Bioanal. Chem. 2009, 396, 327-338. [CrossRef]

30. Crowley, H.C.; Culvenor, C.C.J. Alkaloid assays of Heliotropium europaeum L. Aust. J. Appl. Sci. 1956, 7, 359-364.

31. Bolechová, M.; Cáslavský, J.; Pospíchalová, M.; Kosubová, P. UPLC-MS/MS method for determination of selected pyrrolizidine alkaloids in feed. Food Chem. 2015, 170, 265-270. [CrossRef]

32. Mulder, P.P.; Klijnstra, M.D.; Goselink, R.M.; Van Vuuren, A.M.; Cone, J.W.; Stoopen, G.; Hoogenboom, R.L. Transfer of pyrrolizidine alkaloids from ragwort, common groundsel and viper's bugloss to milk from dairy cows. Food Addit. Contam. 2020, 37, 1906-1921. [CrossRef]

33. Powis, G.; Svingen, B.A.; DeGraw, C. Iron-EDTA stimulated reduction of indicine N-oxide by the hepatic microsomal fraction, isolated hepatocytes, and the intact rat. Biochem. Pharmacol. 1982, 31, 293-299. [CrossRef] 